\title{
COEFFICIENT INEQUALITIES FOR CERTAIN UNIVALENT FUNCTIONS
}

\author{
TADAYUKi SEKINE AND ShIGEYOSHI OWA
}

Abstract. We introduce certain subclasses of univalent functions that are starlike of order $\alpha$ and convex of order $\alpha$. We obtain coefficient inequalities for the functions belong to the subclasses. Using the coefficient inequalities we give some example s of such univalent functions. Also distortion inequalities and convolution properties are determined for the subclasses.

Mathematics subject classification (1991): 30C45.

Key words and phrases: Analytic functions, univalent functions, starlike functions of order $\alpha$, convex functions of order $\alpha$, coefficient inequalities, distortion inequalities, convolutions.

\section{REFERENCES}

[1] S. K. ChatterJea, On starlike functions, J. Pure Math. 1(1981), 23-26.

[2] A. SCHILD AND H. SILVERMAN, Convolutions of univalent functions with negative coefficients, Ann. Univ. M. Curie-Sklodowska, Sect. A 12(1975), 99 - 106.

[3] H. Silverman, Univalent functions with negative coefficients, Proc. Amer. Math. Soc. 51(1975), 109 116.

[4] T. SEKINE AND T. YAMANAKA, Starlike functions and convex functions of order $\alpha$ with nagative coefficients, Math. Sci. Res. Hot-Line 1(1997), 7-12.

[5] H. M. SRIVAstava And S. Owa(Editors), Current Topics in Analytic Function Theory, Word Scientific Publishing Company, Singapore, New Jersey, London, and Hong Kong, 1992.

[6] H. M. SRIVAstaVA, S. OWA AND S. K. ChatTERJEA, A note on certain classes of starlike functions, Rend. Sem. Mat. Univ. Padova, Vol.77(1987), 115-124. 